\title{
Distribusi dan Luas Stomata pada Tanaman Hias Monokotil
}

\section{(Distribution and Area of Stomata in Monocot Ornamental Plants)}

\author{
Ersa Oktaviani, Entin Daningsih*
}

(Diterima Desember 2020/Disetujui Desember 2021)

\begin{abstract}
ABSTRAK
Tanaman hias memberi keindahan pada lingkungan sekitar. Udara yang segar tercipta di sekitar tanaman. Hal ini berkaitan dengan transpirasi yang berhubungan dengan distribusi dan luas stomata. Penelitian ini mengukur distribusi dan luas stomata pada tanaman monokotil yang digunakan sebagai tanaman hias. Desain eksperimen menggunakan rancangan acak lengkap (RAL) faktorial dengan lima ulangan. Enam jenis tanaman monokotil dan tiga bagian tanaman (atas, tengah, dan bawah) adalah faktor utama. Interaksi antara jenis dan bagian tanaman adalah faktor kombinasi. Distribusi dan luas stomata diukur menggunakan metode replika dan mikrometer. Data dianalisis menggunakan sistem analisis statistik model RAL faktorial dan ditindaklanjuti dengan uji beda nyata terkecil jika ada perlakuan yang berbeda nyata. Distribusi stomata dikorelasikan dengan luas stomata untuk mencermati hubungan keduanya. Jenis tanaman, bagian tanaman, dan kombinasi keduanya berpengaruh nyata pada distribusi dan luas stomata. Tanaman lili paris (Chlorophytum comosum (Thumb) Jacq.) memiliki distribusi stomata tertinggi (20,53\%) dibandingkan dengan yang lainnya, dengan luas stomata $291,89 \mu^{2}$. Sementara, bagian atas tanaman memiliki distribusi tertinggi dan berbeda dari bagian tengah dan bawah. Distribusi stomata tertinggi berada di bagian atas tanaman $(15,02 \%)$ dan terrendah di bagian bawah tanaman $(11,96 \%)$, sedangkan luas stomata terkecil pada bagian atas tanaman $\left(687,62 \mu \mathrm{m}^{2}\right)$ dan terluas bagian bawah tanaman $\left(813,88 \mu \mathrm{m}^{2}\right)$. Distribusi stomata berkorelasi terbalik dengan luas stomata baik jenis tanaman, bagian tanaman, dan kombinasi keduanya.
\end{abstract}

Kata kunci: distribusi stomata, luas stomata, monokotil, tanaman hias

\section{ABSTRACT}

Ornamental plants give beauty to the surrounding environment. Fresh air is created around the plant. It is concerned with transpiration which relates to the distribution and extent of stomata. The study measured the distribution and extent of stomata in monocot plants used as houseplants. The experimental design used a complete randomized design (RAL) factorial with five replications. The main factors were six types of monocot plants and three parts of plants (top, middle, and bottom). The interaction between plant types and parts was a combination factor. The distribution and area of the stomata were measured using replica methods and micrometers. The data was analyzed using the factorial RAL model statistical analysis system and followed up with the smallest real different test for significant treatment. The distribution of stomata was correlated with the stomata area to observe the relationship between the two. Plant types, plant parts, and combinations of both have a noticeable effect on the stomata distribution and area. The Paris lilies (Chlorophytum comosum (Thumb) Jacq.) have the highest stomata distribution $(20.53 \%)$ compared to others, with a stomata area of $291.89 \mu \mathrm{m} 2$. Meanwhile, the top part of the plant has the highest distribution and differs from the middle and bottom. The highest stomata distribution is at the top of the plant (15.02\%) and lowest at the bottom (11.96\%), while the smallest stomata area is at the top of the plant (687.62 $\mu \mathrm{m} 2)$ and the widest is at the bottom $(813.88 \mu \mathrm{m} 2)$. The stomata distribution correlates inversely with the stomata area of both plant types, plant parts, and a combination of both.

Keywords: ornamental plants, monocotyledon, stomatal area, stomatal distribution

\section{PENDAHULUAN}

Tanaman hias pada umumnya sering dijumpai baik di halaman maupun di dalam rumah sebagai penambah keindahan dan kesegaran untuk sekitaran rumah. Tanaman bukan hanya berfungsi untuk itu saja

Program Studi Pendidikan Biologi, Jurusan Pendidikan Matematika dan IImu Pengetahuan Alam, Fakultas Keguruan dan IImu Pendidikan, Universitas Tanjungpura, Jl. Profesor Dokter H. Hadari Nawawi, Bansir Laut, Pontianak, Kalimantan Barat 78115

* Penulis Korespondensi:

Email: entindaningsih@fkip.untan.ac.id melainkan juga berperan penting dalam hal kelembapan udara. Efek yang dirasakan salah satunya adalah memengaruhi cuaca panas di lingkungan rumah. Kelembapan udara terjadi karena transpirasi, dan transpirasi sangat berkaitan dengan stomata.

Stomata merupakan modifikasi dari sel epidermis daun berupa sepasang sel penjaga yang bisa menimbulkan celah sehingga uap air dan gas dapat dipertukarkan antara bagian dalam stomata dan lingkungan (Fahn 1991). Stomata umumnya terdapat pada bagian bawah daun, tetapi pada beberapa jenis tumbuhan, stomata dapat dijumpai pada permukaan atas dan bawah daun. Ada pula tumbuhan yang hanya 
mempunyai stomata pada permukaan atas daun, yaitu pada bunga lili air. Tumbuhan air yang daunnya terapung di permukaan air hanya mempunyai stomata di bagian atas, dan tumbuhan yang terendam air tidak memiliki stomata sama sekali. Pada dikotil berdaun lebar, stomata tersebar secara acak, sedangkan pada monokotil berdaun sempit, stomata memanjang, tersusun dalam baris-baris teratur sejajar dengan panjang daun (Lakitan 1993).

Distribusi stomata pada setiap tanaman berbedabeda. Keadaan tersebut dipengaruhi oleh beberapa faktor, yaitu faktor internal berupa perbedaan luas permukaan daun pada tanaman, penutupan stomata, jumlah dan ukuran stomata, perbedaan bentuk stomata, jumlah daun, kerapatan, dan perilaku stomata. Faktor eksternal yang memengaruhi stomata didominasi oleh radiasi matahari dan suhu (Putriani et al. 2019). Haryanti (2010) menunjukkan bahwa naungan yang berbeda dapat memengaruhi panjang dan lebar pori stomata pada permukaan atas daun tetapi tidak memengaruhi jumlah dan lebar stomata permukaan bawah meski tidak memengaruhi panjang dan lebar pori stomata permukaan bawah daun.

Peneltian sebelumnya oleh Diah dan Sunarseh (2018) mengenai jumlah dan ukuran stomata ditunjukkan bahwa apabila semakin banyak jumlah stomata, semakin kecil luas stomata, begitu juga sebaliknya. Penelitian tersebut belum terkait pengaruh jenis tanaman, bagian tanaman, dan kombinasi jenis dan bagian tanaman pada distribusi dan luas stomata pada spesies yang berbeda. Penelitian ini dimaksudkan untuk mengkaji pengaruh jenis, bagian tanaman, dan kombinasi keduanya pada distribusi dan luas stomata, serta hubungannya pada tanaman monokotil.

\section{METODE PENELITIAN}

\section{Bahan dan Alat}

Percobaan dilaksanakan di Laboratorium Pendidikan Biologi FKIP Universitas Tanjungpura, menggunakan enam jenis tanaman monokotil. Rancangan acak lengkap (RAL) faktorial yang diterapkan terdiri atas dua faktor; faktor utama berupa jenis dan bagian tanaman, serta faktor kombinasi jenis dan bagian tanaman. Pengamatan atas jenis dan bagian tanaman masing-masing diulang lima kali dengan menggunakan media tanam yang sama. Sampel diambil dari bagian atas, tengah, dan bawah tanaman untuk diukur distribusi dan luas stomatanya. Alat yang digunakan adalah mikroskop, mikrometer objektif, mikrometer okuler, kaca benda, polybag, handcounter, dan kamera telpon genggam. Bahan yang digunakan adalah replika stomata keenam jenis tanaman hias monokotil: adam-hawa (Rhoeo discolor Hance), bakung (Crynum asiaticum L.), hanjuang (Cordyline fruticosa A. Chev), lili paris (Chlorophytum comosum (Thunb) Jacq.), song of india (Dracaena

reflexa Lam.), dan sri rejeki (Aglaonema crispum (Pit. \& Man.

Perhitungan distribusi stomata menggunakan rumus Meidner \& Mainsfield (1968) (dalam Nurten 2014) dengan menghitung jumlah stomata per unit area dan jumlah sel epidermis per unit area dengan rumus:

$$
\mathrm{SI}=\frac{\text { jumlah sel stomata perunit area }}{\text { jumlah stomata perunit area }+ \text { jumlah sel epidermis perunit area }} \times 100
$$

Keterangan:

SI adalah indeks stomata untuk menetapkan distribusi stomata per unit area

Distribusi dihitung berdasarkan replika stomata yang telah dibuat dan diamati di bawah mikroskop dengan perbesaran $10 \times 10$. Selanjutnya hasil pengamatan replika stomata difoto menggunakan kamera. Dari foto yang didapat, dihitung jumlah stomata dan sel epidermis dengan cara membagi bidang menjadi empat kuadran. Penghitungan menggunakan handcounter. Selanjutnya luas stomata dihitung menggunakan rumus Eberly (2016), yaitu

$$
\text { Luas stomata }=\pi \times a \times b .
$$

Keterangan:

$\pi=3,14$

$a=$ Jari-jari panjang stomata

$b=$ Jari-jari lebar stomata.

Luas stomata dihitung berdasarkan panjang dan lebar sel penjaga, yang diukur menggunakan mikrometer yang sudah dikalibrasi menggunakan rumus (Hidayati 2010):

$$
\begin{aligned}
& \text { Skala pada mikrometer okuler : } \frac{A}{B} \times 0,01 \mathrm{~mm} \times 1000 \\
& \mu \mathrm{m}
\end{aligned}
$$

Keterangan:

A

$B$

$0,01 \mathrm{~mm}$

1000
= Skala pada mikrometer objektif yang berimpitan pada sisi kanan

= Skala pada mikrometer okuler antara dua garis yang berimpit pada mikrometer objektif

= Nilai setiap skala pada micrometer objektif (dalam mm)

= Nilai konversi milimeter ke mikrometer. Pengukuran menggunakan mikroskop dengan perbesaran $10 \times 40$

Selanjutnya data yang diperoleh dari hasil perhitungan distribusi dan luas stomata dianalisis dengan dua tahapan pada setiap analisis data. Data diolah menggunakan aplikasi SAS versi 6.12 tahun 1996 dengan model RAL faktorial dan dianalisis varian (Anova). Jika data yang diperoleh menunjukkan hasil yang nyata, analisis dilanjutkan dengan uji beda nyata terkecil (LSD) dengan rumus (Hanafiah 2010): 


$$
\text { LSD }=t_{0.05 \text { dfe } X} \sqrt{\frac{2 \mathrm{MSE}}{r}}
$$

\section{Keterangan:}

$\mathrm{t}_{0.05}=$ Nilai distribusi $t$ dengan tingkat galat $0,05 \%$ MSE = Rata-rata galat dan rulangan

Pada tahap berikutnya, dilakukan korelasi untuk mengetahui hubungan antara distribusi dan luas stomata dengan menggunakan korelasi Pearson (Thoifah 2016):

$$
\mathrm{r}=\frac{n \sum x y-\left(\sum \mathrm{x}\right)\left(\sum \mathrm{y}\right)}{\sqrt{\left\{( n \sum x ^ { 2 } - ( \sum ( x ) ^ { 2 } ) \} \left\{\left(n \sum y^{2}-\left(\sum(y)^{2}\right\}\right.\right.\right.}}
$$

Keterangan:

$r \quad=$ Nilai korelasi yang dicari

$n \quad=$ Jumlah subjek

$\sum x=$ Jumlah dari variabel $x$

$\sum y=$ Jumlah dari variabel $y$

$\sum x^{2}=$ Kuadrat dari jumlah variabel $x$

$\sum y^{2}=$ Kuadrat dari jumlah variabel $y$

$\sum x y=$ Hasil kali dari jumlah variabel $x$ dan $y$

Untuk mengetahui kuat lemahnya hubungan tersebut, koefisien korelasi perlu untuk diinterpretasikan (Sugiyono 2015).

\section{HASIL DAN PEMBAHASAN}

Hasil analisis data distribusi dan luas stomata dari enam jenis tanaman monokotil dan tiga bagian tanaman, yaitu atas, tengah, dan bawah, telah didapatkan distribusi dan luas stomata (Tabel 1). Berdasarkan hasil faktorial RAL dengan menggunakan SAS, jenis tanaman berpengaruh nyata pada distribusi stomata. Rata-rata distribusi stomata secara berurutan adalah lili paris (20,53\%), bakung (19,02\%), adamhawa $(16,21 \%)$, hanjuang $(9,467 \%)$, song of india $(7,211 \%)$, dan sri rejeki $(5,843 \%)$. Bagian tanaman juga berpengaruh nyata pada distribusi stomata. Rerata distribusi stomata pada bagian atas adalah $15,02 \%$, bagian tengah $12,25 \%$, dan bagian bawah $11,96 \%$. Demikian juga, kombinasi jenis tanaman dan bagian tanaman berpengaruh nyata pada distribusi stomata. Rata-rata distribusi stomata tertinggi pada tanaman lili paris secara beturut-turut dari bagian atas ke bawah ialah 21,89\%, 20,52\%, dan 19,19\%. Sementara untuk tanaman bakung adalah $23,96 \%$, $17,89 \%$, dan $15,22 \%$. Pada tanaman adam-hawa, urutannya ialah $16,63 \%, 16,23 \%$, dan $15,38 \%$; pada hanjuang: $12,65 \%, 8,256 \%$, dan 8,032\%. Keadaannya pada tanaman song of india adalah $8,166 \%, 7,620 \%$, dan 5,848\%; dan pada tanaman sri rejeki: $6,834 \%$, $5,714 \%$, dan $4,982 \%$. Secara keseluruhan terlihat kecenderungan menurun dari bagian atas ke bagian bawah di setiap jenis tanaman.
Berdasarkan analisis sidik ragam, rata-rata luas stomata secara berturut-turut ialah adam-hawa $\left(1642,30 \mu \mathrm{m}^{2}\right)$, sri rejeki $\left(1183,21 \mu \mathrm{m}^{2}\right)$, bakung $\left(834,62 \mu \mathrm{m}^{2}\right)$, song of india $\left(464,75 \mu \mathrm{m}^{2}\right)$, lili paris $\left(291,89 \mu \mathrm{m}^{2}\right)$, dan hanjuang $\left(124,15 \mu \mathrm{m}^{2}\right)$ (Tabel 2). Bagian tanaman pun berpengaruh nyata pada luas stomata. Bagian yang paling luas stomatanya berturut ialah bagian bawah $\left(813,88 \mu \mathrm{m}^{2}\right)$, bagian tengah $\left(768.96 \mu \mathrm{m}^{2}\right)$, dan bagian atas $\left(687,62 \mu \mathrm{m}^{2}\right)$.

Demikian pula, kombinasi jenis tanaman dan bagian tanaman berpengaruh nyata pada luas stomata. Rata-rata luas stomata kombinasi jenis tanaman dan bagian tanaman pada spesies adamhawa dari yang tertinggi ke terendah: bagian bawah $1814,56 \mu \mathrm{m}^{2}$, bagian tengah $1669,40 \mu \mathrm{m}^{2}$, dan bagian atas 1442,94 $\mu^{2}$. Sementara itu, untuk tanaman Bakung: bagian bawah $944,884 \mu \mathrm{m}^{2}$, bagian tengah $785,802 \mu \mathrm{m}^{2}$, dan bagian atas 773,164 $\mu \mathrm{m}^{2}$. Keadaannya pada tanaman hanjuang ialah bagian bawah 141,786 $\mu \mathrm{m}^{2}$, bagian tengah 121,234 $\mu \mathrm{m}^{2}$, dan bagian atas $109,418 \mu \mathrm{m}^{2}$. Untuk tanaman lili paris, gambarannya ialah bagian bawah 332,716 $\mu \mathrm{m}^{2}$, bagian tengah $295,794{\mu \mathrm{m}^{2}}^{2}$, dan bagian atas 247,162 $\mu \mathrm{m}^{2}$, sementara untuk tanaman song of india secara berurutan yaitu bagian bawah mempunyai luas stomata sebesar $546,724 \mu \mathrm{m}^{2}$, bagian tengah sebesar $445,564 \mu \mathrm{m}^{2}$ dan bagian atas sebesar 401,966 $\mu^{2}$. Rata-rata luas stomata kombinasi jenis tanaman dan bagian tanaman Sri Rejeki secara berurutan yaitu bagian bawah mempunyai luas stomata sebesar $1261,72 \mu \mathrm{m}^{2}$, bagian tengah sebesar $1180,46 \mu \mathrm{m}^{2}$, dan bagian atas $1107,44 \mu \mathrm{m}^{2}$.

Berdasarkan hasil perhitungan korelasi Pearson (Tabel 3), korelasi keenam jenis tanaman monokotil memiliki koefisien negatif (-) dengan distribusi dan luas stomata. Berikut ini adalah urutan korelasi dari yang tertinggi ke yang terendah. Pada jenis tanaman adamhawa: bagian atas $-0,54$, bagian tengah $-0,70$, dan bagian bawah $-0,79$; pada bakung: bagian atas $-0,36$, bagian tengah $-0,70$, dan bagian bawah $-0,71$; hanjuang: bagian atas $-0,34$, bagian tengah $-0,45$, dan bagian bawah $-0,47$; lili paris: bagian atas $-0,29$, bagian tengah $-0,71$, dan bagian bawah $-0,55$; song of india: bagian atas -0.54 , bagian tengah $-0,57$, dan bagian bawah $-0,82$; sri rejeki: bagian atas $-0,58$, bagian tengah $-0,71$, dan bagian bawah $-0,95$. Secara umum, korelasi antara distribusi dan luas stomata cenderung meningkat dari bagian atas ke bagian bawah tanaman, kecuali pada lili paris.

Berdasarkan analisis distribusi stomata pada (Tabel 1), distribusi stomata berbeda-beda pada setiap tanaman. Rata-rata distribusi stomata tertinggi ialah pada lili paris, diikuti bakung, adam-hawa, hanjuang, song of india, dan sri rejeki (20,53\%, 19,02\%, 16,21\%, $9,467 \%, 7,211 \% 5,843 \%$ ). Distribusi stomata yang dihitung adalah berdasarkan jumlah stomata dibagi dengan jumlah stomata ditambah dengan jumlah sel epidermis dikali dengan $100 \%$. Perbedaan jumlah stomata disebabkan oleh perbedaan genetik, dilihat dari morfologi daun, dan sangat dipengaruhi oleh 
Tabel 1 Analisis sidik ragam rancangan acak lengkap faktorial distribusi stomata pada enam jenis tanaman monokotil

\begin{tabular}{|c|c|c|}
\hline Variabel & $\begin{array}{c}\text { Rerata } \\
\text { distribusi stomata } \\
(\%)\end{array}$ & Signifikansi \\
\hline Tanaman & & $* * *$ \\
\hline Lili Paris (Chlorophytum comosum (Thunb) Jacq.) & $20,530^{a}$ & \\
\hline Bakung (Crynum asiaticum L.) & $19,020^{\mathrm{ab}}$ & \\
\hline Adam-hawa (Rhoeo discolor Hance) & $16,210^{b}$ & \\
\hline Hanjuang (Cordyline fruticosa A. Chev) & $9,647^{b c}$ & \\
\hline Song India (Dracaena reflexa Lam.) & $7,211^{c}$ & \\
\hline Sri Rejeki (Aglaonema crispum (Pit. \& Man.)) & $5,843^{d}$ & \\
\hline Bagian & & $* * *$ \\
\hline Atas & $15,020^{a}$ & \\
\hline Tengah & $12,250^{a b}$ & \\
\hline Bawah & $11,960^{\mathrm{b}}$ & \\
\hline Kombinasi tanaman dan bagian & & ** \\
\hline Adam-hawa *Atas & 16,630 & \\
\hline Adam-hawa *Tengah & 16,230 & \\
\hline Adam-hawa * Bawah & 15,380 & \\
\hline Bakung (Crynum asiaticum L.) * Atas & 23,960 & \\
\hline Bakung (Crynum asiaticum L.)* Tengah & 17,890 & \\
\hline Bakung (Crynum asiaticum L.) * Bawah & 15,220 & \\
\hline Hanjuang (Cordyline fruticosa A. Chev) * Atas & 12,650 & \\
\hline Hanjuang (Cordyline fruticosa A. Chev) * Tengah & 8,256 & \\
\hline Hanjuang (Cordyline fruticosa A. Chev) * Bawah & 8,032 & \\
\hline Lili Paris (Chlorophytum comosum (Thunb) Jacq.) * Atas & 21,890 & \\
\hline Lili Paris (Chlorophytum comosum (Thunb) Jacq.) ${ }^{*}$ Tengah & 20,520 & \\
\hline Lili Paris (Chlorophytum comosum (Thunb) Jacq.) * Bawah & 19,190 & \\
\hline Song India (Dracaena reflexa Lam.) * Atas & 8,166 & \\
\hline Song India (Dracaena reflexa Lam.) * Tengah & 7,620 & \\
\hline Song India (Dracaena reflexa Lam.) * Bawah & 5,848 & \\
\hline Sri Rezeki Sri rejeki (Aglaonema crispum (Pit. \& Man.)) * Atas & 6,834 & \\
\hline Sri Rezeki Sri rejeki (Aglaonema crispum (Pit. \& Man.)) * Tengah & 5,714 & \\
\hline Sri Rezeki Sri rejeki (Aglaonema crispum (Pit. \& Man.)) * Bawah & 4,982 & \\
\hline
\end{tabular}

Keterangan: ${ }^{* \star *}$ nyata pada $\alpha=0,001,{ }^{* *}$ nyata pada $\alpha=0,01,{ }^{*}$ nyata pada $\alpha=0,05$ dan ns $=$ tidak nyata. Perbedaan huruf di belakang rerata di dalam satu kolom berbeda ketika diuji menggunakan LSD.

tempat tumbuh dan faktor lingkungan. Daun terkena cahaya dengan intensitas tinggi dan panas selama perkembangannya dapat memengaruhi luas permukaan daun, yaitu berukuran lebih kecil dan lebih tebal (Salisbury \& Ross 1992).

Hasil perhitungan rata-rata luas stomata (Tabel 2) menunjukkan luas stomata terbesar secara berturutturut ialah sri rejeki, bakung, adam-hawa, song of india, lili paris, dan hanjuang $\left(5686 \mu \mathrm{m}^{2} ; 4147,5 \mu \mathrm{m}^{2} ; 4077\right.$ $\left.\mu \mathrm{m}^{2} ; 2176,9 \mu \mathrm{m}^{2} ; 1459,4 \mu \mathrm{m}^{2} ; 620,74 \mu \mathrm{m}^{2}\right)$. Stomata pada daun tanaman meningkat karena luas daun cenderung mengecil. Tanaman tersebut memiliki stomata yang lebih banyak tetapi ukuran stomata juga lebih kecil. Tanaman dengan stomata lebih banyak akan menyerap lebih banyak logam berat $\mathrm{Pb}$ dan polutan lain sehingga semakin tinggi $\mathrm{Pb}$ yang diserap semakin rendah klorofil, dan semakin mengecil luas daun, yang berakibat semakin rapat stomata (Satolom 2014). Perubahan ukuran stomata diikuti dengan perubahan kerapatan stomata, diduga erat dengan fungsi penting stomata dalam fotosintesis dan transpirasi. Oleh karena itu, setiap tanaman memiliki ukuran stomata yang berbeda-beda yang dipengaruhi oleh faktor internal seperti sifat genetiknya dan faktor ekstenal, yaitu lingkungan tempat tumbuhan tersebut (Juariah 2014). Menurut Agustini (1994), dalam satu unit area permukaan daun kerapatan stomata sangat beragam, disebabkan oleh perbedaan lingkungan tempat tumbuh dan faktor genetik yang sangat memengaruhi perkembangan stomata.

Analisis atas korelasi enam jenis tanaman monokotil (Tabel 3) dengan berpedoman pada pedoman interpretasi Sugiyono (2015), adalah sebagai berikut. Korelasi pada tanaman adam-hawa pada bagian atas tergolong sedang, bagian tengah dan bawah tergolong kuat. Untuk tanaman bakung: bagian atas rendah, bagian tengah dan bawah tergolong kuat; untuk tanaman hanjuang: bagian atas rendah, bagian tengah dan bawah tergolong sedang. Pada tanaman lili paris: bagian atas dan bawah rendah, bagian tengah kuat. Tanaman song of india: bagian atas dan tengah tergolong sedang, dan bagian bawah kuat. Pada tanaman sri rejeki: bagian atas sedang, bagian tengah kuat, dan bagian bawah sangat kuat.

Semua korelasi adalah korelasi negatif, yang menunjukkan bahwa hubungan antara distrbusi stomata dan luas stomata berbanding terbalik; semakin tinggi distribusi stomata semakin kecil luas stomata, dan sebaliknya. Menurut Price dan Courtois (1991), tanaman beradaptasi terhadap cekaman kekeringan dengan cara mengurangi jumlah stomata. Selain itu, ukuran daun dapat memengaruhi jumlah 
Tabel 2 Analisis sidik ragam rancangan acak lengkap faktorial luas stomata pada enam jenis tanaman monokotil

\begin{tabular}{|c|c|c|}
\hline Variabel & $\begin{array}{l}\text { Rerata luas stomata } \\
\left(\mu \mathrm{m}^{2}\right)\end{array}$ & Signifikansi \\
\hline Tanaman & & *** \\
\hline Adam-hawa (Rhoeo discolor Hance) & $1642,30^{\mathrm{a}}$ & \\
\hline Sri Rejeki (Aglaonema crispum (Pit. \& Man.) & $1183,21^{b}$ & \\
\hline Bakung (Crynum asiaticum L.) & $834,62^{c}$ & \\
\hline Song India (Dracaena reflexa Lam.) & $464,75^{d}$ & \\
\hline Lili Paris (Chlorophytum comosum (Thunb) Jacq.) & 291,89 e & \\
\hline Hanjuang (Cordyline fruticosa A. Chev) & $124,15^{f}$ & \\
\hline Bagian & & *** \\
\hline Atas & $687,62^{\mathrm{a}}$ & \\
\hline Tengah & $768,96^{\mathrm{ab}}$ & \\
\hline Bawah & $813,88^{b}$ & \\
\hline Kombinasi tanaman dan bagian & & ** \\
\hline Adam-hawa (Rhoeo discolor Hance) *Atas & 1442,940 & \\
\hline Adam-hawa (Rhoeo discolor Hance) *Tengah & 1669,400 & \\
\hline Adam-hawa (Rhoeo discolor Hance) * Bawah & 1814,560 & \\
\hline Bakung (Crynum asiaticum L.) * Atas & 773,164 & \\
\hline Bakung (Crynum asiaticum L.) * Tengah & 785,802 & \\
\hline Bakung (Crynum asiaticum L.) * Bawah & 944,884 & \\
\hline Hanjuang (Cordyline fruticosa A. Chev) * Atas & 109,418 & \\
\hline Hanjuang (Cordyline fruticosa A. Chev) * Tengah & 121,234 & \\
\hline Hanjuang (Cordyline fruticosa A. Chev) * Bawah & 141,786 & \\
\hline Lili Paris (Chlorophytum comosum (Thunb) Jacq.) * Atas & 247,162 & \\
\hline Lili Paris (Chlorophytum comosum (Thunb) Jacq.) * Tengah & 295,794 & \\
\hline Lili Paris (Chlorophytum comosum (Thunb) Jacq.) * Bawah & 332,716 & \\
\hline Song India (Dracaena reflexa Lam.) * Atas & 401,966 & \\
\hline Song India (Dracaena reflexa Lam.) * Tengah & 445,564 & \\
\hline Song India (Dracaena reflexa Lam.) * Bawah & 546,724 & \\
\hline Sri Rejeki (Aglaonema crispum (Pit. \& Man.) * Atas & 1107,440 & \\
\hline Sri Rejeki (Aglaonema crispum (Pit. \& Man.) * Tengah & 1180,460 & \\
\hline Sri Rejeki (Aglaonema crispum (Pit. \& Man.) * Bawah & 1261,720 & \\
\hline
\end{tabular}

Keterangan: ${ }^{* * *}$ nyata pada $\alpha=0,001,{ }^{* *}$ nyata pada $\alpha=0,01,{ }^{*}$ nyata pada $\alpha=0,05$ dan ns $=$ tidak nyata. Perbedaan huruf di belakang rerata di dalam satu kolom berbeda ketika diuji menggunakan LSD.

Tabel 3 Korelasi distribusi stomata dan luas stomata pada tiga daun bagian atas, tengah, dan bawah dari enam jenis tanaman dikotil pada cabang terbawah dan diagram

\begin{tabular}{llc}
\hline \multicolumn{1}{c}{ Jenis tanaman } & Bagian & $\begin{array}{c}\text { Korelasi distribusi stomata } \\
\text { dan luas stomata }\end{array}$ \\
\hline \multirow{2}{*}{ Adam-hawa (Rhoeo discolor Hance) } & Aanaman & $-0,54$ \\
& Atas & $-0,70$ \\
Bakung (Crynum asiaticum L.) & Tengah & $-0,79$ \\
& Bawah & $-0,36$ \\
Hanjuang (Cordyline fruticosa A. Chev) & Atas & $-0,70$ \\
& Tengah & $-0,71$ \\
Lili Paris (Chlorophytum comosum (Thunb) Jacq.) & Bawah & $-0,34$ \\
& Atas & $-0,45$ \\
Song India (Dracaena reflexa Lam.) & Tengah & $-0,47$ \\
& Bawah & $-0,29$ \\
Sri Rejeki (Aglaonema crispum (Pit. \& Man.)) & Atas & $-0,71$ \\
& Tengah & $-0,55$ \\
& Bawah & $-0,54$ \\
& Atas & $-0,57$ \\
\hline
\end{tabular}

stomata. Jumlah stomata yang rendah apabila dibandingkan dengan jumlah sel epidermis yang tinggi akan menghasilkan distribusi stomata yang rendah, begitu sebaliknya, jumlah stomata yang tinggi dibandingkan jumlah sel epidermis yang rendah akan menghasilkan distribusi stomata yang tinggi (Mulyani 2006).

Menurut Hakim et al. (2013) nilai kerapatan stomata dapat dipengaruhi oleh besarnya ukuran stomata, semakin kecil ukuran stomata, semakin besar nilai 
kerapatannya sehingga distribusi stomata berkaitan dengan luas stomata. Semakin besar distribusi stomata, semakin kecil luas stomata. Sejalan dengan pendapat Dewi et al. (2015) bahwa ukuran stomata juga berpengaruh pada distribusi stomata, artinya semakin besar ukuran panjang dan lebar stomata. Semakin kecil nilai distribusi stomata, demikian pula sebaliknya.

\section{KESIMPULAN}

Hasil penelitian pada enam jenis tanaman hias monokotil menunjukkan bahwa jenis tanaman, bagian tanaman, dan kombinasi keduanya berpengaruh nyata pada distribusi dan luas stomata. Korelasi antara tiga bagian tanaman, yaitu atas, tengah, dan bawah dari setiap tanaman berkorelasi negatif, dengan nilai beragam.

\section{DAFTAR PUSTAKA}

Dewi NPSR, Eniek K, Pande KS. 2015. Hubungan Kekerabatan 12 Kultivar Brokoli (Brassica oleracea L.) Berdasarkan Karakter Anatomi Stomata. Jurnal Simbiosis III. 1: 291-300.

Eberly D. 2016. The Area of Intersecting Ellipses. [Internet]. [Diunduh 2019 Feb 20]. Tersedia pada: https://www.geometrictools.com/Documentation/Ar ealntersectingEllipses.pdf

Fahn A. 1991. Anatomi Tumbuhan. Yogyakarta (ID): Gajah Mada University Press.

Hakim AR, Dorly, Sri R. 2013. Keragaman dan Analisis Kekerabatan Hoya $s p$. Bertiper Daun Non Sukulen Berdasarkan Karakter Anatomi Daun. Buletin Kebun Raya. 16(1): 6-7.

Haryanti S. 2010. Jumlah dan Distribusi Stomata Pada Daun Beberapa Spesies Tanaman Dikotil dan
Monokotil. Buletin Anatomi dan Fisiologi. XVIII(2): 21-28.

Hidayat EB. 1995. Anatomi Tumbuhan Berbiji. Bandung (ID): Institut Teknologi Bandung.

Juariah L. 2014. Studi Karakter Stomata Beberapa Jenis Tanaman Revegetasi Di Lahan Pasca Penambangan Timah Di Bangka. Widyariset. 17(2): 213-218.

Mulyani S. 2006. Anatomi Tumbuhan. Yogyakarta (ID): Kanisus.

Nurten AVCla, Ahmet AYGÜN. 2014. Determination of Stomatal Density and Distribution on Leaves of Turkish Hazelnut (Corylus avellana L.) Cultivars. 20: 454459. https://doi.org/10.15832/tbd.27845

Price A, Courtois B. 1991. Mapping QTLs Associated with Drought Resistance in Rice; Progress Problem and Prospect. Los Banos (PH): International Rice Research Institute.

Putriani A, Hari P, Reina SW. 2019. Karakteristik Stomata Pada Pohon di Ruang Terbuka Hijau Universitas Tanjungpura Kota Pontianak. Jurnal Hutan Lestari. 7(2): 746-751. https://doi.org/ 10.26418/jhl.v7i2.33629

Rohman F, Hamida R. 2017. Keragaan Karakter Morfologi, Stomata, dan Klorofil Enam Varietas Tembakau Lokal Tulungagung. Buletin Tanaman Tembakau, Serat dan Minyak Industri. 9(1): 15-23. https://doi.org/10.21082/btsm.v9n1.2017.15-22

Satolom AW, Kandowangko NY, Katili AS. 2014. Analisis Kadar Klorofil, Indeks Stomata dan Luas Daun Tumbuhan Mahoni (Swietenia macrophylla King.) pada Beberapa Jalan di Gorontalo. Fakultas MIPA Universitas Negeri Gorontalo: Gorontalo (ID).

Sugiyono. 2015. Metode Penelitian Kuantitatif, Kualitatif, dan R\&D. Bandung (ID): Alfabeta. 